\title{
Comparative Study of $\varepsilon$-Polylysine or Nisin Inhibition Kinetics of Lactococcus lactis and Spoilage Microorganisms in Fresh Flammulina velutipes Fruiting Bodies
}

\author{
Qi Wei $\mathbb{D}^{1,2}$ Xinyuan Pan, ${ }^{3}$ Zhen Jia ${ }^{\mathbb{D}},{ }^{4}$ Changcheng Li, ${ }^{2}$ Bingzhi Chen, ${ }^{2}$ Ting Fang $\mathbb{D},{ }^{2}$ \\ and Yuji Jiang $\mathbb{B}^{2}$ \\ ${ }^{1}$ College of Life Science, Ningde Normal University, Ningde, Fujian 352100, China \\ ${ }^{2}$ College of Food Science, Fujian Agriculture and Forestry University, Fuzhou, Fujian 350002, China \\ ${ }^{3}$ Fujian Anjoy Food Co.,LTD, Xiamen 361000, China \\ ${ }^{4}$ Food Science \& Human Nutrition Department, University of Florida, Gainesville, FL 32611, USA
}

Correspondence should be addressed to Zhen Jia; zhen_jia@uml.edu, Ting Fang; fangting930@163.com, and Yuji Jiang; jyj1209@163.com

Received 21 November 2021; Revised 23 January 2022; Accepted 10 February 2022; Published 1 March 2022

Academic Editor: Efstathios Giaouris

Copyright $\odot 2022$ Qi Wei et al. This is an open access article distributed under the Creative Commons Attribution License, which permits unrestricted use, distribution, and reproduction in any medium, provided the original work is properly cited.

\begin{abstract}
Flammulina velutipes is one of the most important edible mushrooms, which quickly decays with a short shelf life. However, little is known about the effect of $\varepsilon$-polylysine $(\varepsilon-\mathrm{PL})$ or nisin on the survival of Lactococcus lactis (L. lactis) during the storage at constant temperatures. The objective of this study was to investigate the effect of $\varepsilon$-PL or nisin on the growth of L. lactis and background (BK) microorganisms in fresh Flammulina velutipes fruiting bodies (FVFB) and develop mathematical models to predict their growth behavior. The effect of $\varepsilon$-PL $(0.15$ and $0.30 \mathrm{~g} / \mathrm{kg})$ or nisin $(0.10$ and $0.20 \mathrm{~g} / \mathrm{kg})$ on the growth of $L$. lactis and BK microorganisms in FVFB was analyzed at 4,16 , and $20^{\circ} \mathrm{C}$. The lag phase of $L$. lactis was extended, and the specific growth rate was decreased by increasing concentrations of $\varepsilon$-PL or nisin and lowering the temperature. The results showed that $\varepsilon$-PL or nisin could control the growth of L. lactis in FVFB. However, the growth of BK microorganisms was not affected by $\varepsilon$-PL or nisin. The growth of $L$. lactis and BK microorganisms could be successfully described by the reparameterized Gompertz and no lag phase models, respectively. Additionally, $\varepsilon$-PL or nisin could maintain the quality of FVFB by preventing weight loss, color-changing, and decreasing soluble solid content in FVFB at $4^{\circ} \mathrm{C}$. These results suggest that $\varepsilon$-PL or nisin in combination with low temperature may inhibit the growth of L. lactis in FVFB and prevent the decrease in the quality of FVFB.
\end{abstract}

\section{Introduction}

Flammulina velutipes fruiting body (FVFB), known as golden needle mushroom or winter mushroom, is one of the most important edible mushrooms widely cultivated and consumed in China, Japan, and Korea [1]. Compared to other commercial edible mushrooms, such as Agaricus bisporus, Pleurotus eryngii, Pleurotus geesteranus, and Volvariella volvacea, FVFB requires a simple cultivation technique and has unique advantages of fast fruiting and high yield [2, 3]. FVFB has been one of the major mushroom species employed in factory cultivation in many countries. Additionally, FVFB contains a variety of bioactive compounds, such as polysaccharides, essential amino acids, glycoproteins, and sesquiterpenoids. Several studies demonstrated that FVFB had potential bioactivity of hepatoprotection, antitumor, antihyperlipidemia, and immune regulation [4-6]. Because of the aforementioned high nutritional value, medicinal properties, and favorable taste, an increasing number of FVFB have been widely consumed. However, as fresh FVFB is nutritious and contains high moisture content, it favors microorganisms (covering pathogenic and spoilage bacteria) propagating, leading to its decay and short shelf life (1-3 
days) under ambient conditions [7]. Niu et al. [8] indicated that Pseudomonas spp. served as the main native bacteria presented in FVFB.

Lactococcus lactis (L. lactis) has generally been recognized as a safe status by the United States Food and Drug Administration $[9,10]$. A previous study showed that L. lactis was the dominant microflora in FVFB [11]. Zhao et al. [12] reported that the water-soaked and sunken lesions on the mushroom stipes were related to Lactococcus lactis subsp. Therefore, L. lactis might cause the decay of the mushroom. It is worth noting that some species of Lactococcus could be opportunistic pathogens $[13,14]$, posing potential risks for human health. Therefore, it is vital to prevent the growth of L. lactis.

Hurdle technology is a valuable method to ensure food safety by eliminating or controlling the growth of pathogens and extend the shelf life of food products [15]. These hurdles may include temperature, water activity, $\mathrm{pH}$, redox potential, and preservatives. $\varepsilon$-Polylysine $(\varepsilon-\mathrm{PL})$ was approved as a natural antimicrobial food additive by FDA and applied in many commercial food products $[16,17] . \varepsilon$-PL exhibited broad inhibitory activity against microorganisms. $\varepsilon$-PL can be decomposed into lysine in the human body without any side effects and serves as a kind of lysine source. Fukutome et al. [18] reported that there was no obvious pathological tissue change and no possible carcinogenicity was found in rats by dietary administration with $20 \mathrm{mg} / \mathrm{kg}$ of $\varepsilon$-PL. Hiraki et al. [19] reported that $\varepsilon$-PL was practically nontoxic in an acute oral toxicity study in rats, with no mortality up to $5 \mathrm{~g} / \mathrm{kg}$, and was not mutagenic in bacterial reversion assays. Nisin is a natural food preservative. It can be digested into amino acids by proteolytic enzymes in the digestive system after consumption. Ucar et al. [20] demonstrated that nisin could inhibit the food-borne pathogen growth, thereby reducing biogenic amine production in sea bass fillets. In addition, with the treatment of nisin, the shelf life of sea bass fillets could also be extended at $4^{\circ} \mathrm{C}$ [21]. These results suggested that nisin could be applied to avoid pathogen contamination, preserve the organoleptic quality, and extend the shelf life of sea bass fillets [22]. However, no studies have reported the impacts of $\varepsilon-\mathrm{PL}$ and nisin on the growth of L. lactis and native microorganisms in FVFB. Besides, temperature plays a crucial role in microbial growth. However, limited studies systematically investigated the combined effect of temperature and $\varepsilon$-PL or nisin on the survival of L. lactis in FVFB.

Therefore, this study aims to (1) investigate the influences of $\varepsilon$-PL or nisin on the growth of L. lactis and native background microorganisms in FVFB at various isothermal temperatures and (2) develop mathematical models to describe and predict the growth behavior of L. lactis and background microorganisms. Furthermore, the quality characteristics (including weight loss, color, and soluble solid content) of FVFB were evaluated with the presence of $\varepsilon$-PL or nisin during 12 days of storage at $4^{\circ} \mathrm{C}$. The results obtained in this study will be helpful for the food industry to extend the shelf life of FVFB.

\section{Materials and Methods}

2.1. Bacterial Cultures and Preparation. The culture of L. lactis was isolated from FVFB and identified by 16S RNA gene amplification. The isolated L. lactis was transferred to $10 \mathrm{~mL}$ of Luria-Bertani broth (Huankai Microbial Co., Ltd., Guangzhou, China) and incubated at $37^{\circ} \mathrm{C}$ for $20 \mathrm{~h}$. After incubation, the bacteria pellet was harvested by a refrigerated centrifuge $\left(4^{\circ} \mathrm{C}\right.$; Sigma-Aldrich Co., MO) at $4500 \mathrm{rpm}$ for $15 \mathrm{~min}$ and washed three times using $10 \mathrm{~mL}$ of $0.1 \%$ sterile peptone water (PW; Huankai Microbial Co., Ltd., Guangzhou, China). Subsequently, the bacterial culture pellet was resuspended in $10 \mathrm{~mL}$ of $0.1 \%$ sterile PW. Serial dilutions of $L$. lactis were conducted to achieve approximately $10^{5-6} \mathrm{CFU} / \mathrm{mL}$ of the bacterial suspension as a working culture.

\subsection{Sample Preparation and Bacterial Growth. FVFB was} purchased from a local grocery store in Fuzhou, China, and sterilized by irradiating at a dose of $5 \mathrm{kGy}$ (Rice Research Institute, Fujian Academy of Agricultural Sciences, Fuzhou, China). Both $\varepsilon$-PL and nisin were purchased from Zhejiang Silver Elephant Bio-Engineering Co., Ltd. (Zhejiang, China). The preservative solutions of $\varepsilon$-PL $(0.15$ and $0.30 \mathrm{~g} / \mathrm{kg})$ and nisin $(0.10$ and $0.20 \mathrm{~g} / \mathrm{kg})$ were prepared using sterile phosphate-buffered saline (PBS; Huankai Microbial Co., Ltd., Guangzhou, China) and thoroughly mixed by using a stomacher (BagMixer 400W, Interscience Co., Ltd., France) at the maximum speed (10 strokes/s) for $1 \mathrm{~min}$ before use. $25 \mathrm{~g}$ of FVFB were, respectively, submerged in $200 \mathrm{~mL}$ of $0.15 \mathrm{~g} / \mathrm{kg} \mathcal{E}-\mathrm{PL}, 0.30 \mathrm{~g} / \mathrm{kg} \mathcal{E}-\mathrm{PL}, 0.10 \mathrm{~g} / \mathrm{kg}$ nisin, or $0.20 \mathrm{~g} / \mathrm{kg}$ nisin for $2 \mathrm{~min}$. PBS was used as a control. After the treatment, FVFB was immediately removed and dried in a biohood for $1 \mathrm{~h}$. Subsequently, the FVFB samples were inoculated with $0.1 \mathrm{~mL}$ of L. lactis working culture, individually transferred into a sterile plastic filter bag $(20 \times 22 \mathrm{~cm}$, Bkmam Co., Ltd., Changde, China) and then stored at different isothermal temperatures $\left(4,16\right.$, and $\left.20^{\circ} \mathrm{C}\right)$. The samples were periodically retrieved from the incubators to enumerate the concentration of L. lactis. Each sample was homogenized with $225 \mathrm{~mL}$ of $0.1 \%$ sterile PW in the stomacher at $10 \mathrm{strokes} / \mathrm{s}$ for $20 \mathrm{~s} .0 .1 / 1.0 \mathrm{~mL}$ of homogenized samples with or without serial dilution were plated onto de Man-Rogosa-Sharpe agar (MRS; Huankai Microbial Co., Ltd., Guangzhou, China) plates. After incubation for $24 \mathrm{~h}$ at $37^{\circ} \mathrm{C}$, the bacterial colonies on MRS plates were counted and converted to the logarithm of base 10 or natural base, recorded as $\log _{10} \mathrm{CFU} / \mathrm{g}$ or $\mathrm{Ln} \mathrm{CFU} / \mathrm{g}$.

To study the effect of $\mathcal{\varepsilon}$-PL or nisin on native background (BK) microorganisms in FVFB, fresh FVFB samples that were not sterilized and without inoculation of $L$. lactis were taken. The FVFB samples were treated by $\varepsilon$-PL $(0.30 \mathrm{~g} / \mathrm{kg})$ or nisin $(0.20 \mathrm{~g} / \mathrm{kg})$, incubated under the temperature conditions, and removed from incubators using the aforementioned procedures and parameters. The concentrations of BK microorganisms in FVFB samples were counted on tryptic soy agar (Huankai Microbial Co., Ltd., Guangzhou, China) plates after being incubated at $37^{\circ} \mathrm{C}$ for $24 \mathrm{~h}$. The 
bacterial concentrations were also converted to the logarithm of base 10 or natural base, recorded as $\log _{10} \mathrm{CFU} / \mathrm{g}$ or Ln CFU/g.

2.3. Reparameterized Gompertz Model. According to our previous study [13], the reparameterized Gompertz model was more suitable to describe the growth of $L$. lactis in FVFB than the Huang model and Baranyi model. Therefore, in this study, the reparameterized Gompertz model (equation (1)) was developed for predicting the growth of $L$. lactis in FVFB [23]. The no lag phase model (equation (2)) was employed to describe the growth of BK microorganisms [24].

The reparameterized Gompertz model is expressed as

$$
Y(t)=Y_{0}+\left(Y_{\max }-Y_{0}\right) \exp \left\{-\exp \left[\frac{\mu_{\max } e}{Y_{\max }-Y_{0}}(\lambda-t)+1\right]\right\},
$$

where $\lambda$ represents the lag phase duration $(\mathrm{h}), Y(t)$ is the natural logarithm of bacterial count ( $\mathrm{Ln} \mathrm{CFU} / \mathrm{g}$ ), $Y_{0}$ is the natural logarithm of initial bacterial count (Ln CFU/g), $Y_{\max }$ is the natural logarithm of stationary phase bacterial count ( $\mathrm{Ln} \mathrm{CFU} / \mathrm{g}$ ), and $\mu_{\max }$ is the maximum specific growth rate $\left(\mathrm{h}^{-1}\right)$.

The no lag phase model is expressed as

$$
Y(t)=Y_{0}+Y_{\max }-\ln \left[e^{Y_{0}}+\left(e^{Y_{\max }}-e^{Y_{0}}\right) e^{-\mu_{\max } t}\right],
$$

where $Y_{0}, Y_{\max }, Y(t)$, and $\mu_{\max }$ are identical to those used in the reparameterized Gompertz model.

2.4. Modeling and Statistical Analysis. The Integrated Pathogen Modeling Program (IPMP) developed by United States Department of Agriculture (USDA) was used to analyze the growth curves of L. lactis and BK in FVFB at different temperatures [23]. The lag phase duration, specific growth rates, maximum bacterial concentration, confidence intervals, and data analysis were obtained from IPMP analysis.

2.5. Quality Characteristics Analysis. FVFB with similar size, color, and without mechanical damage was selected for the experiment. FVFB was submerged in $200 \mathrm{~mL}$ of $0.30 \mathrm{~g} / \mathrm{kg}$ $\varepsilon$-PL or $0.20 \mathrm{~g} / \mathrm{kg}$ nisin solution for $2 \mathrm{~min}$. PBS treatment was set as control (CK). The treated FVFB was dried in a biohood for $1 \mathrm{~h}$, dispensed in polystyrene trays, and then stored at $4^{\circ} \mathrm{C}$. During the storage, FVFB quality characteristics covering color, weight loss, and soluble solid content were monitored. The color of FVFB was measured by using a colorimeter (Chen Taike Instrument Technology Inc., Beijing, China), and the $L^{*}$ (light/dark) value of each FVFB was recorded for 12 days. Weight loss analysis was conducted as described by Gao et al. [25]. The soluble solid content was determined according to the method reported by Nasiri et al. [26]. In brief, FVFB juice was yielded by grounding using a pestle. Then, the soluble solid content of the juice was analyzed using a refractometer (TH-S9, Tuohe Co., Ltd.,
Shanghai, China). Each experiment was repeated three times.

\section{Results and Discussion}

3.1. Growth of L. lactis and Background Microorganisms in FVFB. Though L. lactis was generally recognized as a safe status and widely used in the food industry, it has been reported that $L$. lactis could be associated with the postharvest decay of mushrooms [27]. Moreover, L. lactis is a homofermentative bacteria, meaning it can produce lactic acid. The lactic acid could lower the $\mathrm{pH}$ value and create suitable conditions for vegetable decay [28]. With the population of $L$. lactis increasing, lactic acid gradually accumulates, causing browning, softening, and deterioration. Furthermore, FVFB typically contains native bacteria, contributing to FVFB's decay and short shelf life. Therefore, $\varepsilon$-PL or nisin was used to control the growth of L. lactis and $\mathrm{BK}$ microorganisms in FVFB at different storage temperatures $\left(4,16\right.$, and $\left.20^{\circ} \mathrm{C}\right)$. The growth data of L. lactis and $\mathrm{BK}$ microorganisms in FVFB treated with $\varepsilon$-PL or nisin at different isothermal storage temperatures were collected and fitted to the reparameterized Gompertz model and no lag phase model, respectively.

Figure 1 shows the growth curves of L. lactis in FVFB samples treated with $\mathcal{E}$-PL at $0,0.15$, and $0.30 \mathrm{~g} / \mathrm{kg}$ (Figure 1(a)) and nisin at $0,0.1$, ad $0.2 \mathrm{~g} / \mathrm{kg}$ (Figure 1(b)) at 4,16 , and $20^{\circ} \mathrm{C}$. Throughout storage at 4,16 , and $20^{\circ} \mathrm{C}$, the concentration of $L$. lactis increased for all treatments exhibiting three phases of growth: lag phase, exponential phase, and stationary phase. The duration of the lag phase and specific growth rate were affected by the incubation temperature, with the lag phase decreasing and the growth rate increasing with the temperature rising. As shown in Figure 1, nisin or $\varepsilon$-PL appeared to interfere with the growth of L. lactis. This result was consistent with the findings reported by Bortolotto et al. [29] and Geornaras et al. [30]. It was also observed that lower temperature and higher concentrations enhanced inhibition efficacy of nisin or $\varepsilon$-PL on the growth of L. lactis synergistically. The reason might be that bacterial cells are more sensitive to nisin or $\varepsilon$-PL at a lower temperature [31]. Additionally, increasing nisin concentrations could promote an increase of cytoplasmic compounds (such as potassium and phosphate ion) leakage, leading to the rise of killed cells $[32,33]$.

Figure 2 displays the growth curves of BK microorganisms in FVFB treated by different concentrations of $\varepsilon$-PL and nisin at temperatures of 4,16 , and $20^{\circ} \mathrm{C}$. It indicates that the BK microorganisms could grow well without the lag phase. As the BK microorganisms naturally exist, they have already adapted to the FVFB. Like L. lactis, decreasing temperature could reduce the growth of BK microorganisms. However, the growth behaviors of BK microorganisms in FVFB treated by nisin are similar to those without nisin treatment, suggesting that $\varepsilon$-PL or nisin has no effect on BK microorganisms. The reason might be that the BK microorganisms in FVFB are formed by Gram-negative bacteria (such as Pseudomonas aeruginosa) [8]. Nisin has no or little 

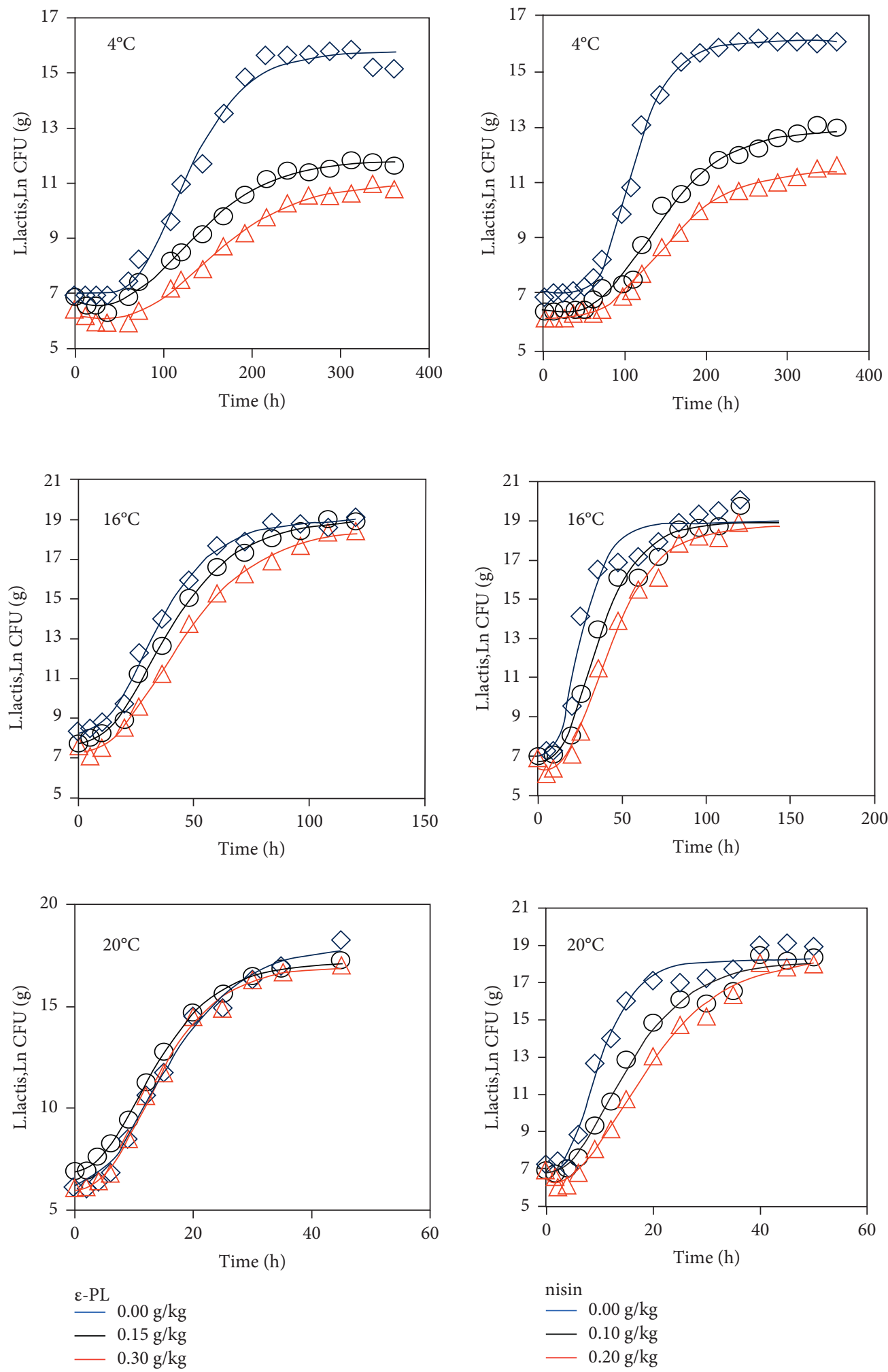

Figure 1: Growth of L. lactis in FVFB and curve-fitting at 4, 16, and $20^{\circ} \mathrm{C}$ : (a) $\varepsilon$-PL treated and (b) nisin treated. Solid line: reparameterized Gompertz model; symbol: observed growth data.

inhibitory effect on Gram-negative bacteria $[34,35]$. It has been widely reported that $\varepsilon$-PL has an effective lethal effect on Gram-positive and Gram-negative bacteria [36]. However, in our study, $\varepsilon$-PL exhibited no impact on BK microorganisms, which is inconsistent with those previously reported by other researchers [16, 37]. BK microorganisms might contain some species of Gram-negative bacteria which could resist $\mathcal{E}$-PL. 

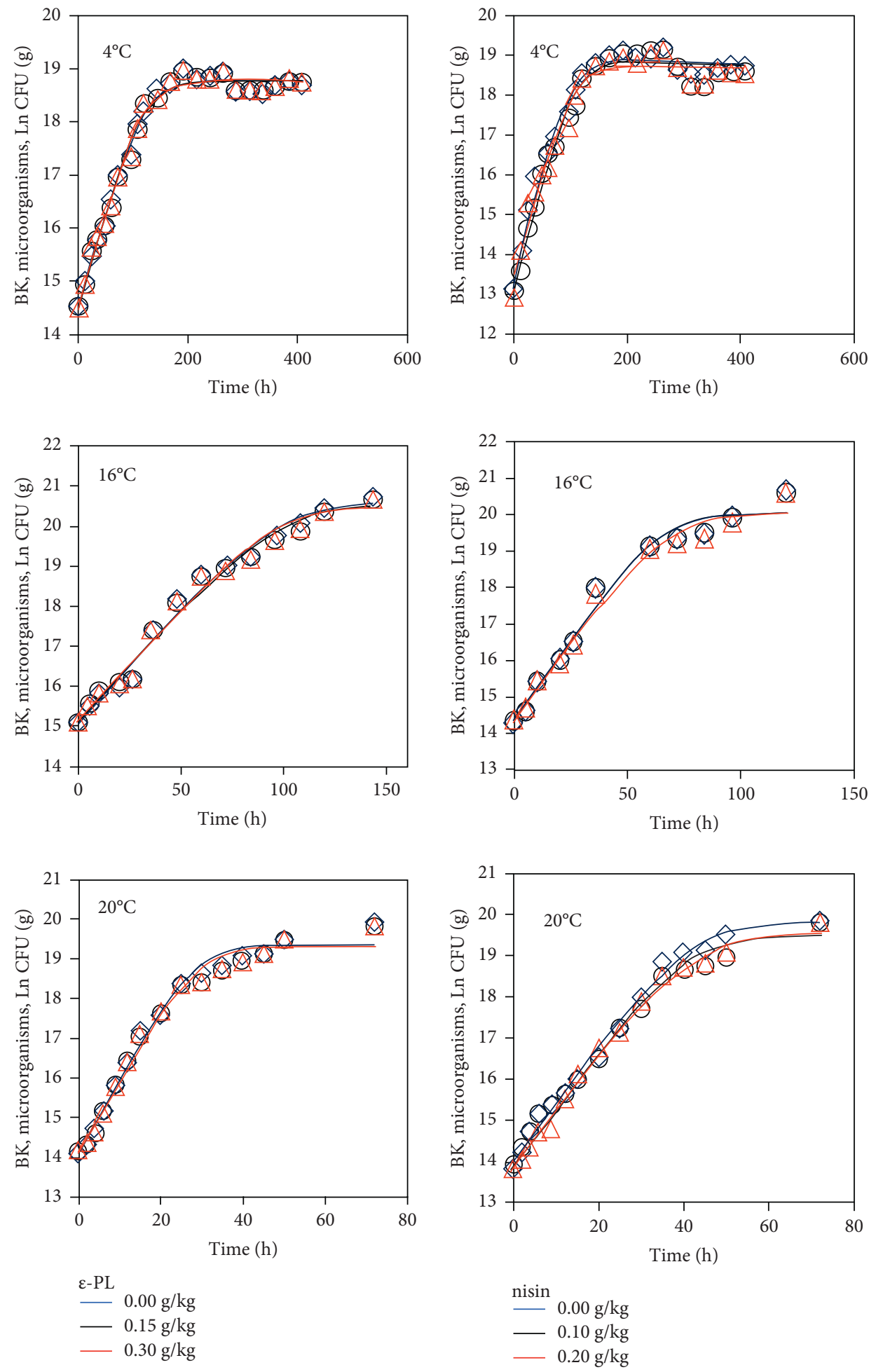

FIGURE 2: Growth of BK microorganisms in FVFB and curve-fitting at 4, 16, and $20^{\circ} \mathrm{C}$ : (a) $\varepsilon$-PL treated and (b) nisin treated. Solid line: no lag phase model; symbol: observed growth data.

3.2. Mathematical Modeling. As depicted in Figure 1, the reparameterized Gompertz model shows good fits to the observed growth curves of L. lactis in FVFB with or without nisin or $\varepsilon$-PL treatment. The growth kinetic parameters of L. lactis estimated by the reparameterized Gompertz model are listed in Table 1 . At 4,16 , and $20^{\circ} \mathrm{C}$, the lag phases of
L. lactis were extended from 69.240, 11.563, and $3.474 \mathrm{~h}$, in the absence of $\varepsilon$-PL to $76.904,13.309$, and $4.703 \mathrm{~h}$, when $0.30 \mathrm{~g} / \mathrm{kg}$ of $\varepsilon$-PL were used. Similarly, as the concentration of nisin varied from 0 to $0.20 \mathrm{~g} / \mathrm{kg}$, the bacterial lag phases were increased from $67.693,11.159$, and 3.549 to 76.816 , 16.732, and $5.419 \mathrm{~h}$. By inspection of Table 1 and Figure 1, it 


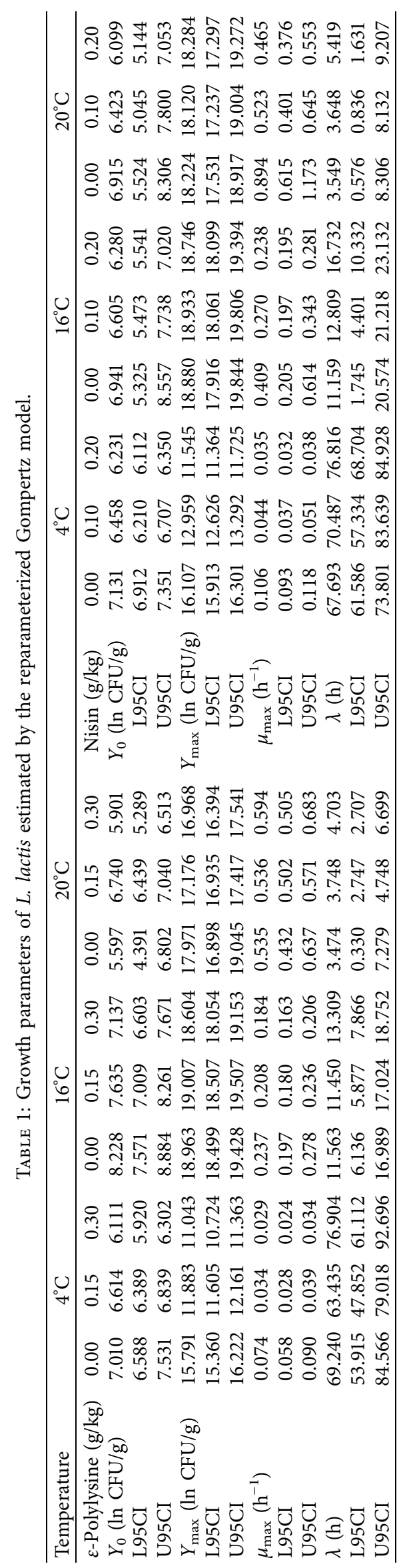




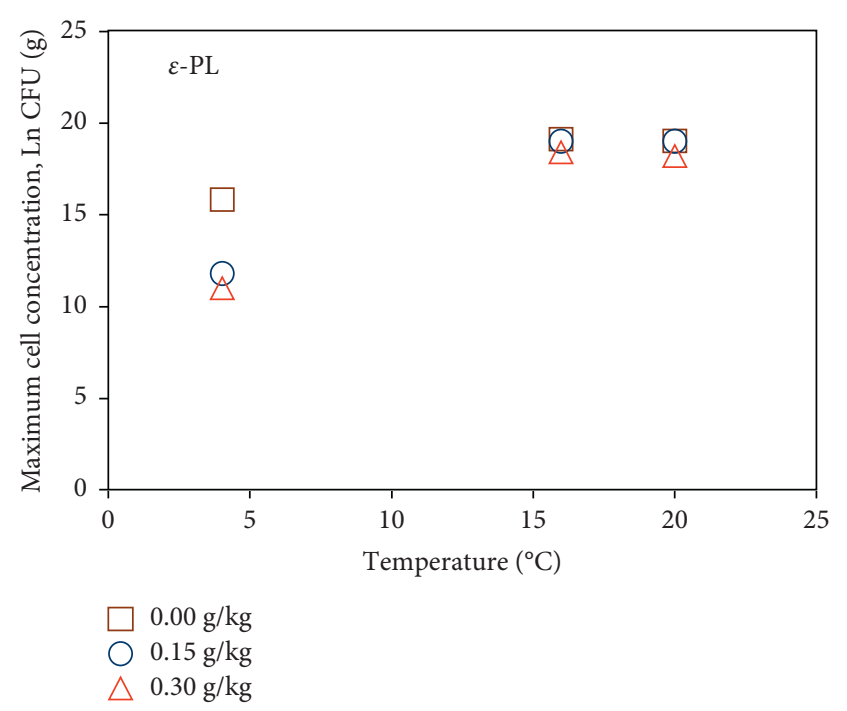

(a)
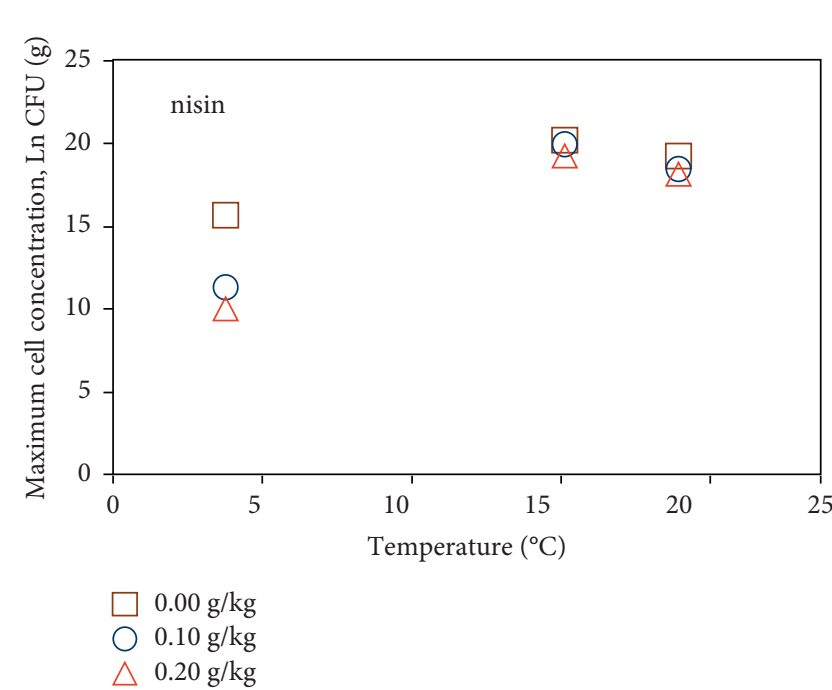

$0.00 \mathrm{~g} / \mathrm{kg}$

$\triangle 0.20 \mathrm{~g} / \mathrm{kg}$

FIgURE 3: The maximum population of L. lactis in FVFB: (a) $\varepsilon$-PL treated and (b) nisin treated.

appeared that $L$. lactis in FVFB samples treated with $\mathcal{\varepsilon}$-PL or nisin exhibited longer lag times than those in control samples $(\mathrm{CK})$ at the same temperatures, suggesting that the addition of $\varepsilon$-PL or nisin to FVFB could delay the growth of L. lactis in FVFB. It has been previously reported and verified that nisin is effective in the lag phase extension of bacteria $[38,39]$. In our previous study, $\varepsilon$-PL also exhibited an influence on the increase of bacterial lag phase [40]. A similar result was also reported by Qian et al. [41]. In addition, temperature also played an essential role in increasing the lag phase of L. lactis. The lower the temperature was, the longer the lag phase was. As bacterial cells could be damaged by $\varepsilon$-PL, nisin, or temperature [42], a longer time was needed to recover, leading to an increase of lag phase. The specific growth rates $\left(\mu_{\max }\right)$ of $L$. lactis in CK were $0.074,0.208$, and $0.535 \mathrm{~h}^{-1}$ at 4,16 , and $20^{\circ} \mathrm{C}$, which were $0.045,0.053$, and $0.059 \mathrm{~h}^{-1}$ higher than those in $0.30 \mathrm{~g} / \mathrm{kg} \varepsilon$-PL-treated FVFB. When nisin concentration was enhanced to $0.20 \mathrm{~g} / \mathrm{kg}, \mu_{\max }$ of $L$. lactis were decreased to $0.035,0.238$, and $0.465 \mathrm{~h}^{-1}$ at 4 , 16 , and $20^{\circ} \mathrm{C}$, respectively. The results indicated that nisin played a role in hindering bacterial growth rate. Similar phenomena were found by Qian et al. [41] and Prado-Acosta et al. [43]. Moreover, $\varepsilon$-PL or nisin could decrease $\mu_{\max }$ of L. lactis in FVFB with the decrease in temperature, suggesting that $\varepsilon$-PL or nisin could control the growth of L. lactis in FVFB. The antibacterial effect of $\varepsilon$-PL or nisin against L. lactis in FVFB at $4^{\circ} \mathrm{C}$ was more substantial than 16 and $20^{\circ} \mathrm{C}$. These results demonstrated that both $\mathcal{E}$-PL and nisin could cooperate with temperature, exhibiting effectiveness against L. lactis by increasing lag phase and decreasing growth rate.

Figure 3 shows the maximum bacterial populations of L. lactis in FVFB. The estimated maximum concentrations of L. lactis ranged between 11.043 and $19.007 \mathrm{Ln} \mathrm{CFU/g}$ (Table 1 and Figure 3). Overall, the maximum concentrations of $L$. lactis showed a light declining trend for all treatments as the storage temperature decreased. At high temperatures $\left(16\right.$ and $20^{\circ} \mathrm{C}$ ), the maximum concentrations of L. lactis were not affected by nisin or $\varepsilon$-PL. However, at a low temperature $\left(4^{\circ} \mathrm{C}\right)$, in comparison with control, the maximum populations of $L$. lactis were reduced by around 3.908 and $4.748 \mathrm{Ln} \mathrm{CFU/g}$ in samples with 0.15 and $0.30 \mathrm{~g} / \mathrm{kg}$ of $\varepsilon$-PL (Figure 3(a)) and by 3.148 and $4.562 \mathrm{Ln} \mathrm{CFU/g} \mathrm{in}$ samples with 0.10 and $0.20 \mathrm{~g} / \mathrm{kg}$ of nisin (Figure 3(b)). These results indicated that the maximum bacterial populations of L. lactis in FVFB were associated with storage temperatures and the concentrations of $\mathcal{\varepsilon}$-PL and nisin. $\mathcal{E}$-PL and nisin, at their highest levels of 0.3 and $0.2 \mathrm{~g} / \mathrm{kg}$, exhibited the strongest antibacterial activities at $4^{\circ} \mathrm{C}$ among all storage temperatures.

The experimental growth data of $\mathrm{BK}$ microorganisms were fitted to the no lag phase model, and the estimated bacterial growth parameters are presented in Table 2. As shown in Figure 2, the no lag phase model was suitable for describing the growth behavior of $\mathrm{BK}$ microorganisms in FVFB with/without $\varepsilon$-PL or nisin addition at 4,16 , and $20^{\circ} \mathrm{C}$. As shown in Table 2 and Figure 2, the specific growth rate of BK microorganisms was not affected by $\mathcal{E}$-PL or nisin. BK microorganisms could reach maximum population densities of around $18.702-20.601 \mathrm{Ln} \mathrm{CFU} / \mathrm{g}$ at $4-20^{\circ} \mathrm{C}$ (Table 1). Under the same temperature condition, no difference of maximum bacterial populations was observed among samples with all treatments (Figure 4 ). These results indicated that $\varepsilon$-PL or nisin has no effect on inhibiting the growth of BK microorganisms in FVFB.

3.3. Analysis of Quality Characteristics. The quality characteristics of FVFB, including weight loss, color, and soluble solid content, are illustrated in Figure 5. As fresh FVFB is high in moisture content (approximately 90\%), weight loss is perceived as one of the main factors of FVFB degradation during storage. The loss of weight could be relative to the tissue shrank in FVFB. Nasiri et al. [26] reported that weight 


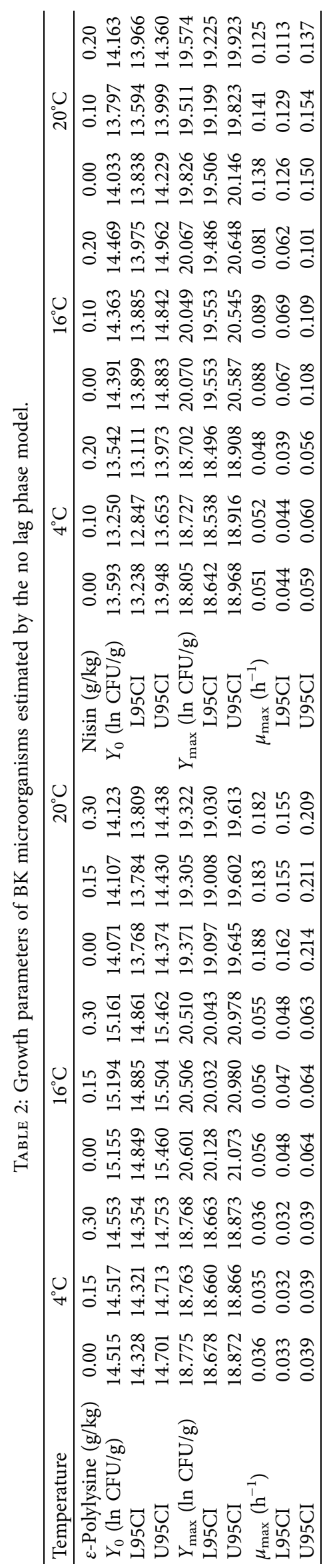




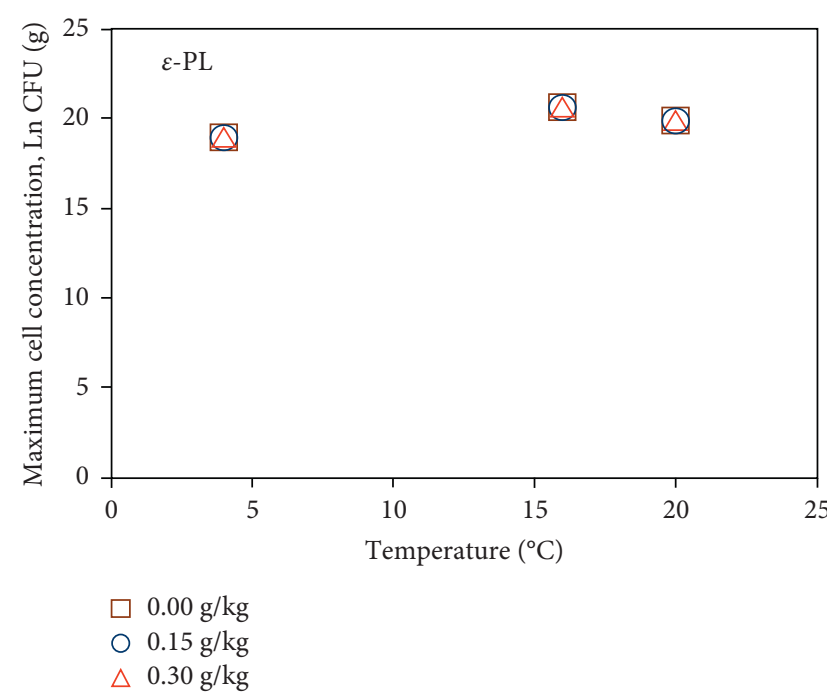

(a)

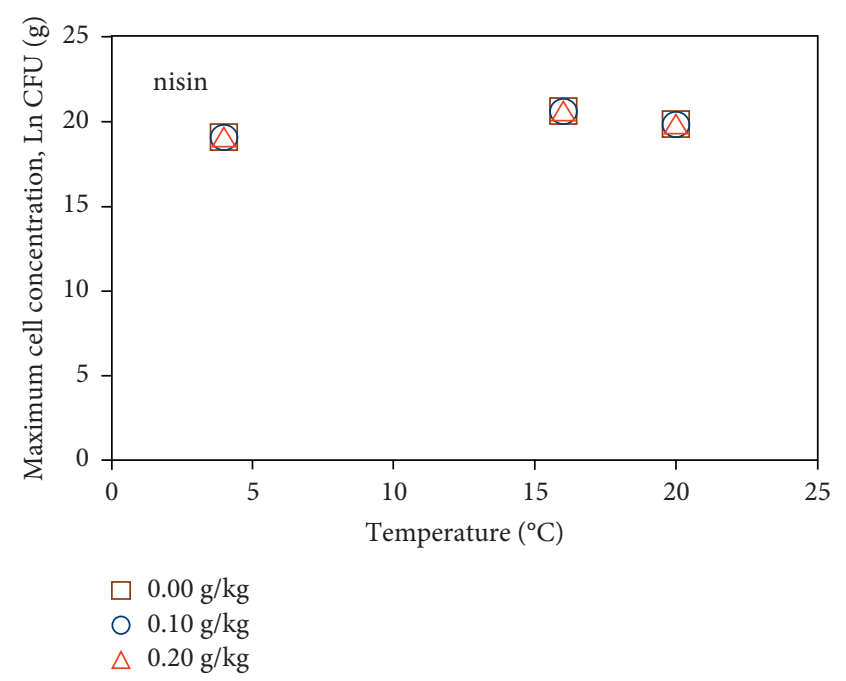

(b)

FIGURE 4: The maximum population of BK microorganisms in FVFB: (a) $\varepsilon$-PL treated and (b) nisin treated.

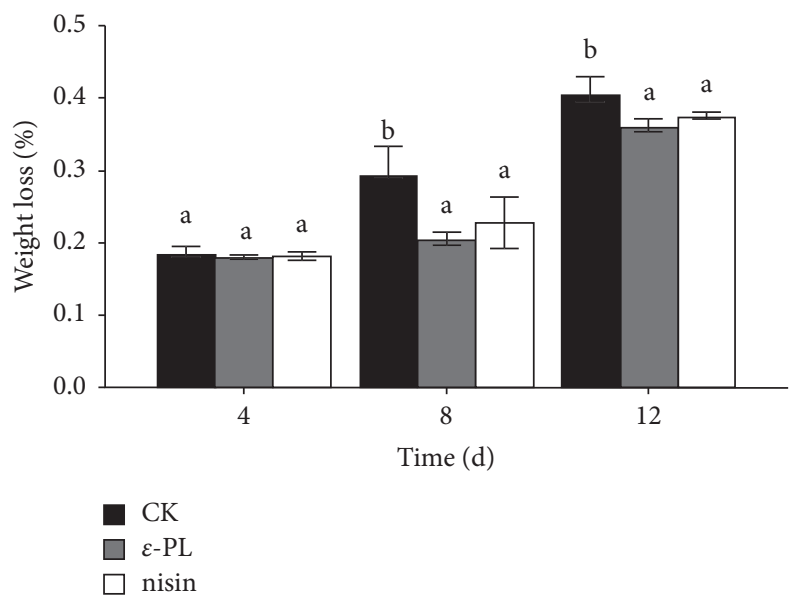

(a)

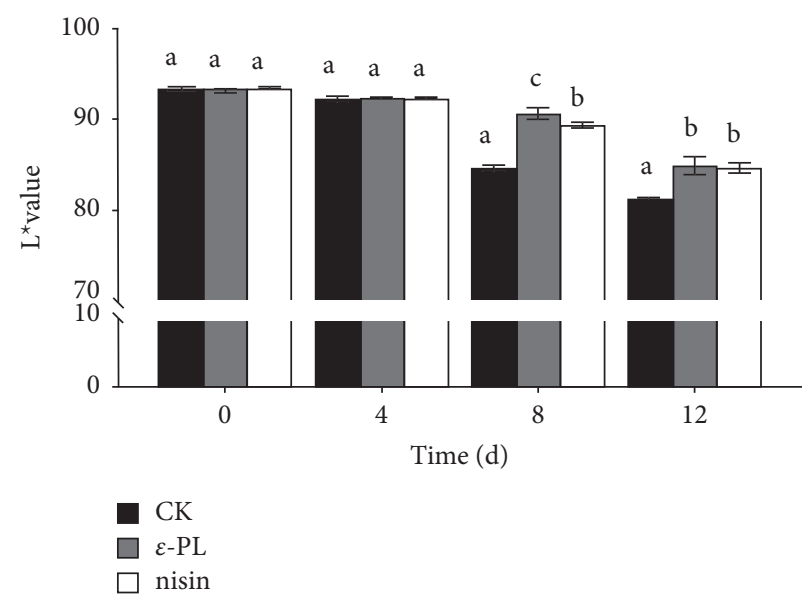

(b)

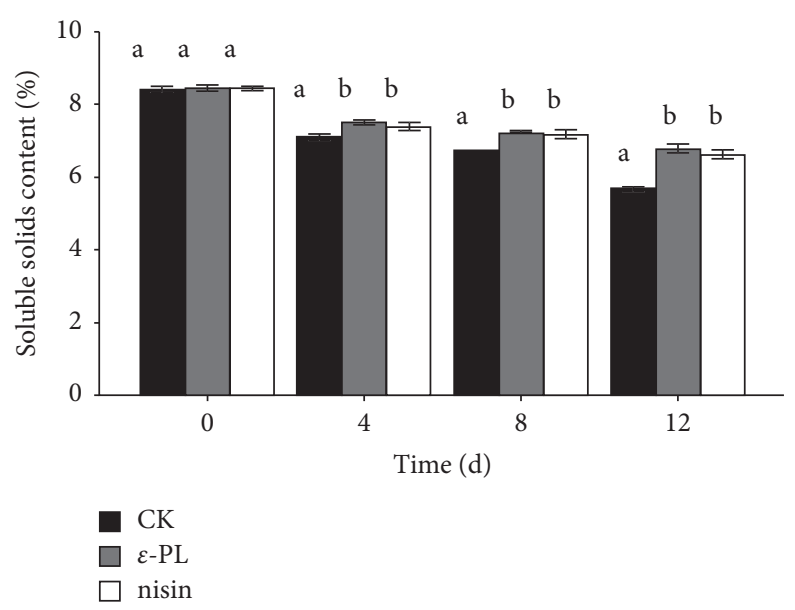

(c)

FIGURE 5: Changes of weight loss, color, and soluble solid content in FVFB. CK: FVFB treated with PBS; $\varepsilon$-PL: FVFB treated with 0.30 g/kg $\varepsilon$-PL; Nisin: FVFB treated with $0.20 \mathrm{~g} / \mathrm{kg}$ nisin. 
loss was associated with the unprotected thin epidermal structure and transpiration rates of Agaricus bisporus, which might provide a favorable environment for the growth of microorganisms. Additionally, microorganisms could destroy the fresh mushroom by breaking down the intracellular matrix and reducing the central vacuole, causing partial cell collapse. Figure 5(a) displays the weight loss shift for 12-day storage at $4^{\circ} \mathrm{C}$. As shown in Figure 5(a), there was no significant difference in weight loss between $\varepsilon$-PL, nisin, and $\mathrm{CK}$ samples during 4-day storage at $4^{\circ} \mathrm{C}$. However, in the period of 8-12-day storage at $4^{\circ} \mathrm{C}$, the weight loss of FVFB was significantly prevented by $\varepsilon$-PL or nisin $(P<0.05)$, in comparison with CK samples.

The color parameter lightness $\left(L^{*}\right)$ is used as a sign of FVFB darkening. Figure 5(b) shows the $L^{*}$ value change of FVFB during storage for $0,4,8$, and 12 days. Compared to CK samples, $\varepsilon$-PL or nisin could significantly increase the $L^{*}$ value of FVFB $(P<0.05)$ after $8-12$-day storage at $4^{\circ} \mathrm{C}$. The result suggests that $\varepsilon$-PL or nisin exhibited an impact on preventing the browning processing of FVFB.

Soluble solid content enhancement was gradual during the storage time in $\varepsilon$-PL- or nisin-treated samples (Figure 5(c)). In the absence of $\varepsilon$-PL or nisin, soluble solid content displayed a decreasing tendency during storage. Furthermore, within 4-12 days of storage, the soluble solid content in CK FVFB was much lower than that in $\varepsilon$-PL- or nisin-treated FVFB. It suggests that $\varepsilon$-PL or nisin could prevent the decrease of soluble solid content in FVFB. The high value of soluble solid content was a sign of retarding the senescence process [44], which indicated that $\varepsilon$-PL or nisin was beneficial to extend the shelf life of FVFB.

The above results are in accordance with the findings of Barbosa et al. [45], who indicated that nisin maintained the physicochemical characteristics of mangoes throughout the storage period, and Fan et al. [46], who demonstrated that $\varepsilon$-PL showed a positive effect on preventing weight loss and color change of lettuce.

\section{Conclusion}

This study was conducted to investigate the effects of $\varepsilon$-PL and nisin on the growth of $L$. lactis and $\mathrm{BK}$ microorganisms in FVFB at various constant temperatures $\left(4,16\right.$, and $\left.20^{\circ} \mathrm{C}\right)$. It was found that $\varepsilon$-PL or nisin could interact with temperature to inhibit the growth of L. lactis. With temperature decreasing and $\varepsilon$-PL or nisin concentration increasing, the inhibitory effect of $\varepsilon$-PL or nisin was strengthened. It was also found that $\varepsilon$-PL $(0.15$ and $0.30 \mathrm{~g} / \mathrm{kg})$ or nisin $(0.10$ and $0.20 \mathrm{~g} / \mathrm{kg}$ ) could extend the lag phase duration and reduce the specific growth rate. However, the growth of $\mathrm{BK}$ microorganisms in FVFB was not affected by $\varepsilon$-PL ( 0.15 and $0.30 \mathrm{~g} / \mathrm{kg})$ or nisin $(0.10$ and $0.20 \mathrm{~g} / \mathrm{kg})$. The developed reparameterized Gompertz model and no lag phase model could accurately predict the growth of $L$. lactis and $\mathrm{BK}$ in FVFB with or without $\varepsilon$-PL or nisin treatment, respectively. Moreover, the $\varepsilon$-PL or nisin could effectively restrain the decrease of weight loss, soluble solid content, and $L^{*}$ value of FVFB during the storage period at $4^{\circ} \mathrm{C}$ compared with the control of untreated FVFB.

\section{Data Availability}

The data used to support the findings of this study are included within the article.

\section{Additional Points}

Applications. The results obtained in this study will be helpful for the food industry to extend the shelf life of Flammulina velutipes fruiting bodies.

\section{Ethical Approval}

The study does not involve any human or animal testing.

\section{Conflicts of Interest}

The authors declare that they have no conflicts of interest.

\section{Acknowledgments}

This project was supported by the Key Cultivating Program of Ningde Normal University (Grant no. 2020ZDK03).

\section{References}

[1] D. L. Fang, W. J. Yang, B. M. Kimatu, and Q. Hu, "Effect of nanocomposite-based packaging on the storage stability of mushrooms (Flammulina velutipes)," Innovative Food Science and Emerging Technologies, vol. 33, pp. 489-497, 2015.

[2] S. R. Liu, S. Z. Zheng, and W. R. Zhang, "Modeling the effects of $\varepsilon$-poly-L-lysine, chitosan, and temperature as hurdles on the prevention and control of indicator bacteria in a submerged culture of the commercially important Flammulina velutipes for liquid spawn production," Scientia Horticulturae, vol. 270, no. 25, Article ID 1094414, 2020.

[3] S. Attaran Dowom, S. Rezaeian, and H. R. Pourianfar, "Agronomic and environmental factors affecting cultivation of the winter mushroom or enokitake: achievements and prospects," Applied Microbiology and Biotechnology, vol. 103, no. 6, pp. 2469-2481, 2019.

[4] Y. Wang and H. Zhang, "Advances in the extraction, purification, structural-property relationships and bioactive molecular mechanism of Flammulina velutipes polysaccharides: a review," International Journal of Biological Macromolecules, vol. 167, no. 15, pp. 528-538, 2021.

[5] R. Zhao, Q. Hu, G. Ma et al., "Effects of Flammulina velutipes polysaccharide on immune response and intestinal microbiota in mice," Journal of Functional Foods, vol. 56, no. 11, pp. 255-264, 2019.

[6] C. Tang, P. C. X. Hoo, L. T. H. Tan et al., "Golden needle mushroom: a culinary medicine with evidenced-based biological activities and health promoting properties," Frontiers in Pharmacology, vol. 7, pp. 1-27, 2016.

[7] C. Shi, Y. Wu, D. Fang et al., "Effect of nanocomposite packaging on postharvest senescence of Flammulina velutipes," Food Chemistry, vol. 246, no. 25, pp. 414-421, 2018.

[8] Y. X. Niu, J. M. Yun, Y. Bi et al., "Predicting the shelf life of postharvest Flammulina velutipes at various temperatures based on mushroom quality and specific spoilage organisms," Postharvest Biology and Technology, vol. 176, Article ID 111235, 2020. 
[9] Food and Drug Administration (FDA), History of the GRAS List and SCOGS Reviews, FDA, Maryland, USA, 2012.

[10] S. Wessels, L. Axelsson, E. De Vuyst et al., "The lactic acid bacteria, the food chain, and their regulation," Trends in Food Science \& Technology, vol. 15, no. 10, pp. 498-505, 2004.

[11] Q. Wei, X. Pan, J. Li, Z. Jia, T. Fang, and Y. Jiang, "Isolation and molecular identification of the native microflora on Flammulina velutipes fruiting bodies and modeling the growth of dominant microbiota (Lactococcus lactis)," Frontiers in Microbiology, vol. 12, Article ID 664874, 2021.

[12] Y. Zhao, P. Li, H. Hu, Y. Wang, Y. Sun, and K. Huang, "Postharvest decay of the cultivated mushroom Pleurotus eryngii caused by Lactococcus lactis subsp. Lactis," Journal of Plant Pathology, vol. 95, no. 2, pp. 247-253, 2013.

[13] M. Aguirre and M. D. Collins, "Lactic acid bacteria and human clinical infection," Journal of Applied Bacteriology, vol. 75, no. 2, pp. 95-107, 1993.

[14] P. T. Mannion and M. M. Rothburn, "Diagnosis of bacterial endocarditis caused by Streptococcus lactis and assisted by immunoblotting of serum antibodies," Journal of Infection, vol. 21, no. 3, pp. 317-318, 1990.

[15] F. Iordache, I. Gheorghe, V. Lazar et al., "Nanostructurated materials for prolonged and safe food preservation," Food Preservation, vol. 9, pp. 305-335, 2017.

[16] Y.-Q. Li, Q. Han, J.-L. Feng, W.-L. Tian, and H.-Z. Mo, "Antibacterial characteristics and mechanisms of $\varepsilon$-poly-lysine against Escherichia coli and Staphylococcus aureus," Food Control, vol. 43, pp. 22-27, 2014.

[17] X. You, J. E. Einson, C. L. Lopez-Pena et al., "Food-grade cationic antimicrobial $\varepsilon$-polylysine transiently alters the gut microbial community and predicted metagenome function in CD-1 mice," Npj Science of Food, vol. 1, no. 8, pp. 8-10, 2017.

[18] A. Fukutome, M. Kashima, and M. Aiuchi, "A combined chronic toxicity and carcinogenicity study of polylysine powder in rats by peroral dietary administration," Clinical Reports, vol. 29, pp. 1416-1431, 1995.

[19] J. Hiraki, T. Ichikawa, S.-I. Ninomiya et al., "Use of ADME studies to confirm the safety of $\varepsilon$-polylysine as a preservative in food," Regulatory Toxicology and Pharmacology, vol. 37, no. 2, pp. 328-340, 2003.

[20] Y. Ucar, Y. Ozogul, M. Durmus, and F. Ozogul, "The effects of nisin on the growth of foodborne pathogens and biogenic amine formation: in vivo and in vitro studies," Food Bioscience, vol. 43, no. 2, Article ID 101266, 2021.

[21] Y. Ucar, Y. Özogul, F. Özogul, M. Durmuş, and A. R. Köşker, "Effect of nisin on the shelf life of sea bass (Dicentrarchus labrax L.) fillets stored at chilled temperature $\left(4 \pm 2^{\circ} \mathrm{C}\right)$," Aquaculture International, vol. 28, no. 2, pp. 851-863, 2020.

[22] Y. Ucar, Y. Ozogul, F. Ozogul, M. Durmus, A. R. Kosker, and E. K. Boga, "The impact of different levels of nisin as a biopreservative agent on the chemical, sensory and microbiological quality of vacuum-packed sea bass (Dicentrarchus labrax) fillets stored at $4 \pm 2^{\circ} \mathrm{C}$," Grasas Y Aceites, vol. 72, pp. 1-12, 2021.

[23] L. Huang, "IPMP 2013-a comprehensive data analysis tool for predictive microbiology," International Journal of Food Microbiology, vol. 171, no. 3, pp. 100-107, 2014.

[24] T. Fang, J. B. Gurtler, and L. Huang, "Growth kinetics and model comparison of Cronobacter sakazakii in reconstituted powdered infant formula," Journal of Food Science, vol. 77, no. 9, pp. E247-E255, 2012.

[25] M. Gao, L. Feng, and T. Jiang, "Browning inhibition and quality preservation of button mushroom (Agaricus bisporus) by essential oils fumigation treatment," Food Chemistry, vol. 149, no. 15, pp. 107-113, 2014.

[26] M. Nasiri, M. Barzegar, M. A. Sahari, and M. Niakousari, "Efficiency of Tragacanth gum coating enriched with two different essential oils for deceleration of enzymatic browning and senescence of button mushroom (Agaricus bisporus)," Food Sciences and Nutrition, vol. 7, no. 4, pp. 1520-1528, 2019.

[27] Y. Zhao, R. Zhu, Y. Wang et al., "Complete genome sequence of Lactococcus lactis subsp. lactis SLPE1-3, a novel lactic acid bacterium causing postharvest decay of the mushroom Pleurotus eryngii," Journal of Plant Pathology, vol. 100, no. 3, pp. 467-476, 2018.

[28] T. Odamaki, J. Z. Xiao, S. Yonezawa, T. Yaeshima, and K. Iwatsuki, "Improved viability of Bifidobacteria in fermented milk by cocultivation with Lactococcus lactis subspecies lactis," Journal of Dairy Science, vol. 94, no. 3, pp. 1112-1121, 2011.

[29] F. C. K. Bortolotto, M. H. D. R. Farfan, N. C. K. Jede, G. M. Danielski, and R. Macedo, "Nisin and $\varepsilon$-poly-L-lysine as natural antimicrobials towards spoilage-associated Lactobacillus plantarum," Food Technology, vol. 51, Article ID e20200423, 2020.

[30] I. Geornaras, Y. Yoon, K. Belk, G. Smith, and J. N. Sofos, "Antimicrobial activity of $\varepsilon$-polylysine against Escherichia coli O157:H7, Salmonella typhimurium, and Listeria monocytogenes in various food extracts," Journal of Food Science, vol. 72, no. 8, pp. 330-334, 2007.

[31] L. V. Thomas and J. W. Wimpenny, "Investigation of the effect of combined variations in temperature, $\mathrm{pH}$, and $\mathrm{NaCl}$ concentration on nisin inhibition of Listeria monocytogenes and Staphylococcus aureus," Applied and Environmental Microbiology, vol. 62, no. 6, pp. 2006-2012, 1996.

[32] N.-E. Chihib, L. Monnerat, J. M. Membre, and J.-L. Tholozan, "Nisin, temperature and $\mathrm{pH}$ effects on growth and viability of Pectinatus frisingensis, a Gram-negative, strictly anaerobic beer-spoilage bacterium," Journal of Applied Microbiology, vol. 87, no. 3, pp. 438-446, 1999.

[33] R. Pattanayaiying, A. H-Kittikun, and C. N. Cutter, "Effect of lauric arginate, nisin $\mathrm{Z}$, and a combination against several food-related bacteria," International Journal of Food Microbiology, vol. 188, no. 1, pp. 135-146, 2014.

[34] K. T. Chung, J. S. Dickson, and J. D. Crouse, "Effects of nisin on growth of bacteria attached to meat," Applied and Environmental Microbiology, vol. 55, no. 6, pp. 1329-1333, 2021.

[35] H. Liu, H. Pei, Z. Han, G. Feng, and D. Li, "The antimicrobial effects and synergistic antibacterial mechanism of the combination of $\varepsilon$-Polylysine and nisin against Bacillus subtilis," Food Control, vol. 47, pp. 444-450, 2015.

[36] T. Yoshida and T. Nagasawa, " $\varepsilon$-Poly-l-lysine: microbial production, biodegradation and application potential," $A p$ plied Microbiology and Biotechnology, vol. 62, no. 1, pp. 21-26, 2003.

[37] L. Wei, R. Wu, C. Wang, and Z. Wu, "Effects of $\varepsilon$-polylysine on Pseudomonas aeruginosa and Aspergillus fumigatus biofilm in vitro," Medical Science Monitor, vol. 23, pp. 4225-4229, 2017.

[38] B. A. Felicio, M. S. Pinto, F. S. Oliveira, M. W. Lempk, A. C. S. Pires, and C. A. Lelis, "Effects of nisin on Staphylococcus aureus count and physicochemical properties of Minas Frescal cheese," Journal of Dairy Science, vol. 98, no. 7, pp. 4364-4369, 2015.

[39] I. F. Kiss, K. Márialigeti, E. Zukál, and J. Makk, "Method for measurement of antibacterial activity of nisin," Bulletin of 
University of Agricultural Sciences and Veterinary Medicine Cluj-Napoca, vol. 64, pp. 1-6, 2007.

[40] Z. Jia, C. Li, T. Fang, and J. Chen, "Predictive modeling of the effect of $\varepsilon$-polylysine hydrochloride on growth and thermal inactivation ofListeria monocytogenesin fish balls," Journal of Food Science, vol. 84, no. 1, pp. 127-132, 2019.

[41] Y. F. Qian, Y. Cheng, X. Ye, Y. Zhao, J. Xie, and S. P. Yang, "Targeting shrimp spoiler Shewanella putrefaciens: application of $\varepsilon$-polylysine and oregano essential oil in Pacific white shrimp preservation," Food Control, vol. 123, Article ID 107702, 2021.

[42] F. Liu, M. Liu, L. Du et al., "Synergistic antibacterial effect of the combination of $\varepsilon$-polylysine and nisin against Enterococcus faecalis," Journal of Food Protection, vol. 78, no. 12, pp. 2200-2206, 2015.

[43] M. Prado-Acosta, S. M. Ruzal, M. C. Allievi, M. M. Palomino, and C. Sanchez Rivas, "Synergistic effects of the Lactobacillus acidophilus surface layer and nisin on bacterial growth," Applied and Environmental Microbiology, vol. 76, no. 3, pp. 974-977, 2010.

[44] M. Jafri, A. Jha, D. S. Bunkar, and R. C. Ram, "Quality retention of oyster mushrooms (Pleurotus florida) by a combination of chemical treatments and modified atmosphere packaging," Postharvest Biology and Technology, vol. 76, pp. 112-118, 2013.

[45] A. A. Barbosa, H. G. Silva de Araújo, P. N. Matos, M. A. Carnelossi, and A. Almeida de Castro, "Effects of nisinincorporated films on the microbiological and physicochemical quality of minimally processed mangoes," International Journal of Food Microbiology, vol. 164, no. 1, pp. 135-140, 2013.

[46] K. Fan, M. Zhang, B. Bhandari, and F. Jiang, "A combination treatment of ultrasound and $\varepsilon$-polylysine to improve microorganisms and storage quality of fresh-cut lettuce," Lebensmittel-Wissenschaft \& Technologie, vol. 113, no. 1, Article ID 108315, 2019. 